\title{
A structural basis for selection and cross- species reactivity of the semi-invariant NKT cell receptor in CD1d/glycolipid recognition
}

\author{
Lars Kjer-Nielsen, ${ }^{1}$ Natalie A. Borg, ${ }^{2}$ Daniel G. Pellicci, ${ }^{1}$ Travis Beddoe, ${ }^{2}$ \\ Lyudmila Kostenko, ${ }^{1}$ Craig S. Clements, ${ }^{2}$ Nicholas A. Williamson, ${ }^{1}$ \\ Mark J. Smyth, ${ }^{3}$ Gurdyal S. Besra, ${ }^{4}$ Hugh H. Reid, ${ }^{2}$ Mandvi Bharadwaj, ${ }^{1}$ \\ Dale I. Godfrey, ${ }^{1}$ Jamie Rossjohn, ${ }^{2}$ and James McCluskey ${ }^{1}$

\begin{abstract}
'Department of Microbiology and Immunology, University of Melbourne, Parkville, Victoria 3010, Australia
${ }^{2}$ The Protein Crystallography Unit, ARC Centre of Excellence in Structural and Functional Microbial Genomics, Department of Biochemistry and Molecular Biology, School of Biomedical Sciences, Monash University, Clayton, Victoria 3800, Australia ${ }^{3}$ Cancer Immunology Program, Peter MacCallum Cancer Centre, St. Andrew's Place, East Melbourne, Victoria 3002, Australia ${ }^{4}$ School of Biosciences, University of Birmingham, Edgbaston, Birmingham B15 2T, England, UK
\end{abstract}

Little is known regarding the basis for selection of the semi-invariant $\boldsymbol{\alpha} \boldsymbol{\beta}$ T cell receptor (TCR) expressed by natural killer T (NKT) cells or how this mediates recognition of CD1dglycolipid complexes. We have determined the structures of two human NKT TCRs that differ in their CDR3 $\beta$ composition and length. Both TCRs contain a conserved, positively charged pocket at the ligand interface that is lined by residues from the invariant TCR $\boldsymbol{\alpha}$ - and semi-invariant $\boldsymbol{\beta}$-chains. The cavity is centrally located and ideally suited to interact with the exposed glycosyl head group of glycolipid antigens. Sequences common to mouse and human invariant NKT TCRs reveal a contiguous conserved "hot spot" that provides a basis for the reactivity of NKT cells across species. Structural and functional data suggest that the CDR3 $\beta$ loop provides a plasticity mechanism that accommodates recognition of a variety of glycolipid antigens presented by CD1d. We propose a model of NKT TCR-CD1dglycolipid interaction in which the invariant CDR3 $\alpha$ loop is predicted to play a major role in determining the inherent bias toward CD1d. The findings define a structural basis for the selection of the semi-invariant $\boldsymbol{\alpha} \boldsymbol{\beta}$ TCR and the unique antigen specificity of NKT cells.

CORRESPONDENCE
James McCluskey:
jamesm1@unimelb.edu.au
OR
Jamie Rossjohn:
Jamie.Rossjohn@med.monash.
edu.au
Abbreviations used: $\alpha-G a l C e r$,
$\alpha$-galactosylceramide; Ag, antigen;
BSA, buried surface area; C, con-
stant; CDR, complementarity-
determining region; hCD1d,
human CD1d; mCD1d, mouse
CD1d; RMS, root mean square;
SPR, surface plasmon resonance;
V, variable.

The CD1 molecules are a cluster of nonpolymorphic, MHC class I-like glycoproteins that present lipid-based antigens to $\alpha \beta$ T cells $(1,2)$. They comprise group I, CD1a, CD1b, CD1c, and CD1e molecules found in humans and the group II CD1d molecule that is expressed in humans, mice, and rats $(1,2)$. CD1d binds both self and foreign glycolipids (3-11), including the glycosphingolipid $\alpha$-galactosylceramide ( $\alpha$-GalCer) (3), an archetypal CD1d ligand that binds well to both human (hCD1d) and mouse CD1d (mCD1d) molecules and is a potent agonist for NKT cells $(6,12,13)$. Recently, the structure of $\alpha$-GalCer complexed with hCD1d and mCD1d was determined $(14,15)$, revealing that the acyl and sphingosine lipid chains of $\alpha-\mathrm{GalCer}$ are buried in the antigen (Ag)-

$\overline{\text { L. Kjer-Nielsen and N.A. Borg contributed equally to this work. }}$ J. McCluskey and J. Rossjohn contributed equally to this work. The online version of this article contains supplemental material. binding cavity, whereas the polar glycosyl head group protrudes from the CD1d cleft, where it is available for TCR interaction.

In contrast with polyclonal $\mathrm{T}$ cell recognition of the group I CD1 molecules (16), T cell recognition of CD1d-glycolipid complexes preferentially selects a semi-invariant TCR with a fixed $\alpha$-chain and restricted $\beta$-chain, exclusively expressed by a subset of $\mathrm{T}$ cells known as NKT cells (17-19). The human invariant NKT cell TCR $\alpha$-chain uses a V $\alpha 24-J \alpha 18$ (TRAV10TRAJ18) (20) rearrangement that encodes a germline-encoded junctional sequence with a single codon deletion at the $\mathrm{V} \alpha-\mathrm{J} \alpha$ junction, preserving amino acid sequence identity among human NKT TCR $\alpha$-chains (12, 17-19). NKT cells are also present in other mammalian species, including mice that express a homologous invariant Vo14-Ja18 (TRAV11-J15) TCR $\alpha$-chain rearrangement (20). Most human NKT cells express V $\beta 11$ (TRBV25-1) (20) 


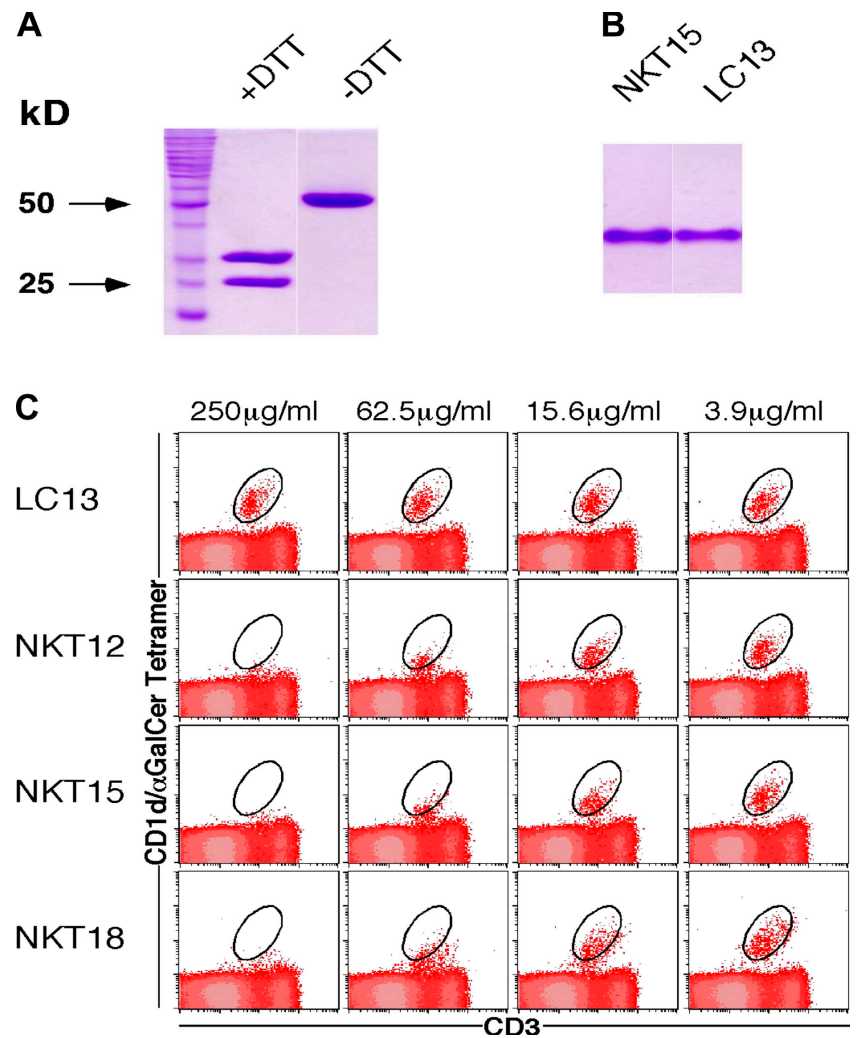

Figure 1. Structural and functional integrity of recombinant soluble NKT TCRs. (A) Purified bacterial NKT15 TCR was analyzed by SDS-PAGE under reducing (+DT, dithiothreitol) and nonreducing $(-D T)$ conditions demonstrating $\alpha \beta$ heterodimers. (B) Native gel electrophoresis of folded $\alpha \beta$ heterodimeric NKT15 and control LC13 TCRs. (C) Recombinant soluble NKT12, NKT15, NKT18, and control LC13 TCRs were tested for their ability to block binding of mouse $C D 1 d / \alpha-G a l C e r$ tetramers to murine thymocytes. Phycoerythrin-conjugated $\mathrm{mCD} 1 \mathrm{~d} / \alpha$-GalCer tetramers were preincubated with the indicated soluble TCRs over a range of TCR

concentrations before staining mouse thymocytes. Cells were analyzed by two-color flow cytometry showing $\mathrm{mCD} 1 \mathrm{~d} / \alpha$-GalCer tetramer staining on the vertical axis and FITC-CD3 (mAb 145-2C11) staining on the horizontal axis. Cells staining positively with $\mathrm{mCD} 1 \mathrm{~d} / \alpha-\mathrm{GalCer}$ tetramer and FITC-CD3 are indicated with a circle.

rearranged to form variable $D \beta-\mathrm{J} \beta$ combinations (17-19), whereas mouse NKT cells typically use either $\mathrm{V} \beta 8.2, \mathrm{~V} \beta 2$, or VB7 (TRBV13-2, BV1, or BV29, respectively) (13, 20-22). The crucial role played by the NKT TCR $\alpha$-chain is highlighted by the lack of NKT cells in TCR J 18 gene-targeted mice (23). Alternatively, the role of $\mathrm{V} \beta$ in NKT cell selection and $\mathrm{Ag}$ recognition appears to be more subtle. For example, mouse NKT cells expressing V $\beta 8.2$ display higher affinity binding toward IgG1-CD1d/ $\alpha$ GalCer dimers than NKT cells expressing V $\beta 7$ (24). These data have been interpreted to mean that complementarity-determining region (CDR) $1 \beta$ and CDR $2 \beta$ may be more important than CDR $3 \beta$ in NKT specificity (24), perhaps by mediating contacts with CD1d. This view is consistent with the high degree of natural variability in CDR3 $\beta$ sequences in NKT cells (25-27) and the comparable affinity of hybrid NKT TCRs substituted with noncognate mouse $\mathrm{V} \beta 8.2$ chains derived from conventional $\alpha \beta$ T cells (28). However, the role of CDR3 $\beta$ in NKT cell specificity is controversial (25) in that some studies of mouse NKT hybridomas and CD1d mutants implicate CDR $3 \beta$ in the fine specificity of NKT Ag recognition $(24,29-31)$, including the suggestion of a novel CDR3 $\beta$ motif in human NKT cells expanded with $\alpha$-GalCer (12). Remarkably, human NKT cells can also recognize mouse CD1d- $\alpha$-GalCer complexes (32) and vice versa, indicating the evolutionary importance of NKT cells in immunity (33).

The structural explanation for selection of the semiinvariant NKT TCR, the role of the CDR $3 \beta$ loops in NKT specificity, and the basis for the reciprocal cross-species reactivity in Ag recognition by human and mouse NKT cells remain unresolved. Here, we describe the structure of two different semi-invariant TCRs, NKT12 and NKT15, from human NKT cells. The findings define a structural basis for the extreme $\alpha \beta$ selection of NKT cell TCRs and indicate a mechanism for how the conformation and plasticity of the CDR3 $\beta$ loops could modulate binding of different CD1dglycolipid antigens. A proposed model of the NKT TCR $-\alpha-$ GalCer complex provides new insights into Ag recognition and cross-species reactivity by NKT TCRs.

\section{RESULTS}

\section{The semi-invariant $\mathrm{T}$ cell receptors}

NKT cells were expanded from PBMCs by stimulation with $\alpha$-GalCer, and cDNA corresponding to the TCR $\alpha$ and $\beta$ gene transcripts was isolated. Three NKT receptors (NKT12, NKT15, and NKT18) were characterized as containing the invariant V $\alpha 24-J \alpha 18$ (TRAV10-TRAJ18) (20). NKT12 and NKT15 had Vß11 (TRBV25-1) (20) rearranged to $\mathrm{D} \beta$ segment TRBD1 and J $\beta$ segment TRBJ2-7 (20), whereas NKT18 V $\beta 11$ was rearranged to D $\beta$ TRBD1 and J $\beta$ TRBJ2-1 (20). All three receptors differed in the

Table I. Amino acid sequences of CDR3 $\beta$ residues in NKT TCRs

\begin{tabular}{|c|c|c|c|}
\hline \multirow[t]{2}{*}{ TCR } & \multicolumn{3}{|c|}{ Gene segment } \\
\hline & $\mathrm{V} \boldsymbol{\beta}$ & $\mathrm{D} \boldsymbol{\beta}+\mathrm{N}$ & $\boldsymbol{J} \beta$ \\
\hline NKT12 & ${ }^{92} \mathrm{CAS}^{94}$ & ${ }^{95}$ TSRRG $^{99}$ & ${ }^{100} \mathrm{SY}^{105}$ EOYFGPGTRLTVT ${ }^{117}$ \\
\hline NKT15 & ${ }^{92}$ CASS $^{95}$ & ${ }^{96} \mathrm{GLRDRGL}^{102}$ & ${ }^{103}{ }^{105}$ EOYFGPGTRLTVT'117 \\
\hline NKT18 & ${ }^{92}$ CASS $^{95}$ & ${ }^{96}$ APGTGD ${ }^{101}$ & ${ }^{102} \mathrm{~N}^{105}$ EQFFGPGTRLTVL ${ }^{117}$ \\
\hline LC13 & ${ }^{92} \mathrm{CASS}^{95}$ & ${ }^{96} \mathrm{LGQA}^{99}$ & ${ }^{100}{ }^{105}$ EOYFGPGTRLTVT 117 \\
\hline
\end{tabular}


length and composition of their CDR3 $\beta$ loops (Table I). Thus, the CDR $3 \beta$ of NKT15 is two residues longer than NKT12 and one residue longer than NKT18. The extracellular domains of the NKT12, NKT15, and NKT18 TCRs were expressed in Escherichia coli, then folded into a native conformation and purified by multiple rounds of chromatography as described in Materials and methods. The quality and function of the recovered protein was assessed by gel filtration size exclusion chromatography, ELISA reactivity with the conformation-dependent $\mathrm{mAb} 12 \mathrm{H} 8$ (anti-C $\alpha / C \beta$ ) (34) (not depicted), SDS-PAGE (Fig. 1 A), and native gel electrophoresis (Fig. $1 \mathrm{~B}$ ). To further confirm that the complexes were in a natural conformation, they were tested for their ability to block binding of mouse CD1d/ $\alpha-$ GalCer tetramers to mouse NKT cells. The assay confirmed that the soluble receptors retained their original antigen reactivity over a comparable dose range (Fig. $1 \mathrm{C}$ ). The NKT18 TCR was used for binding studies only, whereas the structures of the NKT12 and NKT15 TCRs were determined. The NKT12 and NKT15 TCRs were crystallized in an orthorhombic space group and their structures were determined to $2.4 \AA$ and $2.2 \AA$ resolution, respectively. In addition, the NKT15 TCR also crystallized in a trigonal space group, and this crystal form was determined to $2.6 \AA$ resolution. The collection statistics and refinement data are shown in Table II.

Table II. Data collection and refinement statistics

\begin{tabular}{|c|c|c|c|}
\hline & $\begin{array}{c}\text { NKT12 } \\
\text { Orthorhombic }\end{array}$ & $\begin{array}{c}\text { NKT15 } \\
\text { Orthorhombic }\end{array}$ & $\begin{array}{c}\text { NKT15 } \\
\text { Trigonal }\end{array}$ \\
\hline \multicolumn{4}{|l|}{ Data collection } \\
\hline Temperature & $100 \mathrm{~K}$ & $100 \mathrm{~K}$ & $100 \mathrm{~K}$ \\
\hline Space group & $\mathrm{C} 222_{1}$ & $\mathrm{C} 222_{1}$ & $\mathrm{P} 3_{2}$ \\
\hline Cell dimensions $(\AA)(a, b, c)$ & $58.92,131.39,117.80$ & $59.84,131.03,116.85$ & $66.67,66.67,182.41$ \\
\hline Resolution $(\AA ̊)$ & 2.4 & 2.2 & 2.6 \\
\hline Total no. observations & 65,216 & 79,368 & 77,333 \\
\hline No. unique observations & 18,076 & 22,974 & 27619 \\
\hline Multiplicity & 3.60 & 3.45 & 2.80 \\
\hline Data completeness (\%) & $98.7(96.8)$ & $97.5(98.4)$ & $97.5(98.4)$ \\
\hline No. data $>2 \sigma_{1}(\%)$ & $83.2(58.5)$ & $82.5(60.8)$ & $76.6(42.2)$ \\
\hline $1 / \sigma_{1}$ & $19.3(3.8)$ & $15.8(3.9)$ & $10.7(2.3)$ \\
\hline $\mathrm{R}_{\text {merge/sym }}{ }^{\mathrm{a}}(\%)$ & $7.3(41.2)$ & $8.9(42.0)$ & $9.8(54.0)$ \\
\hline \multicolumn{4}{|l|}{ Refinement statistics } \\
\hline \multicolumn{4}{|l|}{ Nonhydrogen atoms } \\
\hline Protein & 3,528 & 3,542 & 7,084 \\
\hline Water & 55 & 123 & 32 \\
\hline Resolution $(\AA)$ & $65.65-2.4$ & $65.51-2.2$ & $60.86-2.6$ \\
\hline$R_{\text {cryst }} \mathrm{b}(\%)$ & 23.0 & 21.0 & 20.7 \\
\hline$R_{\text {free }}{ }^{\mathrm{c}}(\%)$ & 27.1 & 27.8 & 25.6 \\
\hline \multicolumn{4}{|l|}{ RMS deviations from ideality } \\
\hline Bond lengths $(\AA)$ & 0.007 & 0.011 & 0.009 \\
\hline Bond angles $\left({ }^{\circ}\right)$ & 1.05 & 1.28 & 1.20 \\
\hline Dihedrals $\left(^{\circ}\right)$ & 28.57 & 28.82 & 28.69 \\
\hline Impropers $\left({ }^{\circ}\right)$ & 1.25 & 1.33 & 1.27 \\
\hline \multicolumn{4}{|l|}{ Ramachandran plot } \\
\hline Most favored & 90.7 & 89.9 & 87.9 \\
\hline And allowed region (\%) & 9.1 & 9.3 & 10.8 \\
\hline And disallowed region (\%) & 0.2 & 0.8 & 1.3 \\
\hline \multicolumn{4}{|l|}{ B-factors $\left(\AA^{2}\right)$} \\
\hline Average main chain & 33.8 & 28.4 & 41.3 \\
\hline Average side chain & 34.3 & 30.5 & 42.8 \\
\hline Average water molecule & 28.2 & 30.8 & 43.5 \\
\hline RMS deviation bonded Bs & 1.6 & 2.5 & 2.3 \\
\hline
\end{tabular}

Values in parentheses are for the highest resolution shell.

${ }^{\text {a }} R_{\text {merge } / \text { sym }}=\Sigma \mid I_{h k l}-\Sigma\left\langle I_{h k l}\right\rangle / \Sigma I_{h k l}$.

${ }^{\mathrm{b}} R_{\text {cryst }}=\sum_{h k \mid}|| F_{0}|-| F_{c}|| / \sum_{h k l}\left|F_{0}\right|$ for all data except as indicated in footnote "c."

c7.3, 5.2, and 5\% were used for the $R_{\text {free }}$ calculation for NKT12 (orthorhombic), NKT15 (orthorhombic), and NKT15 (trigonal), respectively.

RMS, root mean square. 


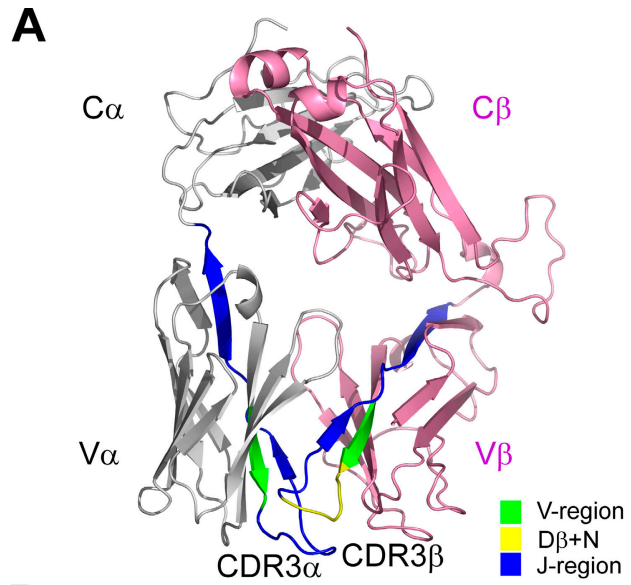

B
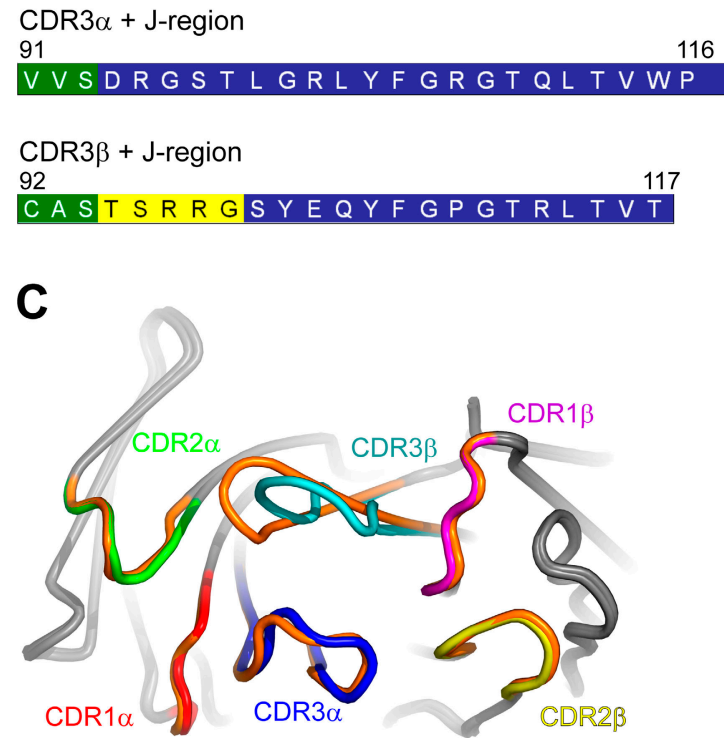

Figure 2. Overview of NKT cell TCR structure showing the conformation of the CDR loops at the Ag-binding interface. (A) Overview of the structure of NKT12 with the $\alpha$-chain and $\beta$-chain shown in gray and pink, respectively. (B) The CDR3 loops of NKT12 are color coded according to their genetic origin. (C) Superimposition of the CDR loops of the NKT12 and NKT15 TCRs depicting the difference in the conformation of CDR3 $\beta$ (NKT12, CDR loops colors are indicated; NKT15, orange).

The overall structure of the NKT12 TCR comprises four immunoglobulin-like domains with a constant (C) and variable $(\mathrm{V})$ domain per chain (Fig. $2 \mathrm{~A})$. The $\mathrm{V}$ domain is composed of three CDRs; together, these six hypervariable loops form a potential ligand-binding site for the NKT12 TCR. Accordingly, the structure of the NKT12 TCR generally resembles that of other $\alpha \beta$ TCRs. The interface between the $\alpha$ - and $\beta$-chains of the NKT12 TCR is extensive (buried surface area $[\mathrm{BSA}]$ of $\approx 4,100 \AA^{2}$ ), with the $\mathrm{V}$ and $\mathrm{C}$ domains packing against each other. The BSA at the $\mathrm{V} \alpha-\mathrm{V} \beta$ and $\mathrm{C} \alpha-$ $\mathrm{C} \beta$ interfaces, $\approx 1,400 \AA^{2}$ and $\approx 2,700 \AA^{2}$, respectively, falls within the range observed previously in other TCR structures $(35,36)$. Comparative structural analyses will be mainly restricted to two intact heterodimeric TCR crystal structures, namely a human nonliganded immunodominant TCR, LC13 $(36,37)$, and the nonliganded murine TCR, 2C $(38$, 39). The root mean square (RMS) for the pairwise superpositions between the NKT12 TCR and the LC13 and 2C TCRs were $1.20 \AA$ (383 residues) and $1.43 \AA$ (345 residues), respectively. As expected, the constant domains of the NKT12 TCR superpose very closely with that of another nonliganded human TCR, LC13 (RMS deviations $0.50 \AA$ and $0.47 \AA$ over the $C \alpha$ and $C \beta$ domains, respectively). However significant differences in juxtaposition between the $\mathrm{V} \alpha$ and $\mathrm{V} \beta$ domains were observed, which reflects the unique interchain pairing of the semi-invariant NKT TCR. For example the V $\beta$ domain of NKT12 is rotated $16.4^{\circ}$ and $13.1^{\circ}$ relative to the $2 \mathrm{C}$ TCR $(38,39)$ and the $\operatorname{LC} 13 \mathrm{TCR}$, respectively $(36,37)$. Moreover, comparative analyses revealed structural divergence within the respective $\mathrm{V} \alpha$ and $\mathrm{V} \beta$ domains. For example, pairwise superpositions between NKT12 V $\alpha$ and the LC13 and 2C V $\alpha$ domains were $1.40 \AA$ (94 residues) and $1.34 \AA$ (92 residues), respectively; whereas the pairwise superpositions between the V $\beta$ domains (LC13, $1.08 \AA$ [98 residues]; 2C, $1.02 \AA$ [103 residues]) revealed that, in comparison, the $\mathrm{V} \alpha$ domain was more divergent than the $\mathrm{V} \beta$ domain. The major structural differences within the $\mathrm{V}$ domains reside in the hypervariable loops and the loop $(69 \alpha-$ $74 \alpha$ ), which impacts not only upon the Ag binding site, but also the $\mathrm{V} \alpha-\mathrm{V} \beta$ pairing.

The NKT12 $\mathrm{V} \alpha-\mathrm{V} \beta$ interface is composed of the $\mathrm{f}-\mathrm{g}$ and the $c-c^{\prime}$ strands, and their interconnecting loops from each domain crossing over each other, and accordingly utilizes both the V $\alpha 24$ and J $\alpha 18$ gene segment of the invariant chain (Supplemental Materials and methods, available at http:// www.jem.org/cgi/content/full/jem.20051777/DC1). The CDR $3 \alpha$ and CDR $3 \beta$ loops sit centrally at this interface, abutting each other (Fig. 2 and Supplemental Materials and methods). At the $\mathrm{V} \alpha-\mathrm{V} \beta$ interface, there are six polar interactions, five water-mediated polar interactions, two salt bridges, and a multitude of van der Waals interactions that include a cluster of aromatic residues (Tyr35 $\alpha$, Phe106 $\alpha$, Tyr33 $\beta$, Tyr35 $\beta$, Tyr107 $\beta$ ) (Table S1, available at http://www.jem. org/cgi/content/full/jem.20051777/DC1). This cluster is largely conserved, although less extensive in the LC13 and 2C TCR structures.

The sequences encoded by the invariant $\mathrm{J} \alpha$ and hypervariable $\mathrm{D} \beta-\mathrm{N}-\mathrm{J} \beta$ region create the CDR3 loops (Fig. 2, A and B). Accordingly, the interface differs slightly between the NKT12 and NKT15 TCRs as a result of the conformation of the different CDR $3 \beta$ loops (Fig. 2 C). Notably, the CDR $1 \alpha$ and $\operatorname{CDR} 2 \alpha$ loops adopt a conformation that is different from previously determined canonical CDR conformations (40), whereas CDR $1 \beta$ and CDR2 $\beta$ adopt canonical conformations $\beta 1-1$ and $\beta 2-1$, respectively (Table S2, available at http://www.jem.org/cgi/content/full/jem.20051777/DC1). The conformation of the CDR $3 \alpha$ loop is well ordered and stabilized by interloop interactions as shown for other highly selected TCRs (34). 
The ligand binding surface contains a preformed cavity suited to Ag binding

The ligand-binding surface of NKT12 contains a central water-filled cavity that is markedly electropositive and $\sim 120 \AA^{3}$ in volume (Fig. 3, A and B). The cavity is lined by residues from CDR $1 \alpha$ and CDR $3 \alpha$ of the invariant NKT $\alpha$-chain, as well as CDR1 $\beta$ and CDR $3 \beta$ of the semi-invariant $\beta$-chain that collectively make several direct and water-mediated interactions with each other (Fig. 3 B). The residues from the invariant $\mathrm{V} \alpha 24-\mathrm{N}-\mathrm{J} \alpha 18$ include the following: Ser30 $\alpha$ and Asn $31 \alpha$ from CDR1 $\alpha$; Arg33 $\alpha$ from the $V \alpha$-framework close to CDR $1 \alpha$; Ser93 $\alpha$ from the CDR3 $\alpha$ V-J junctional

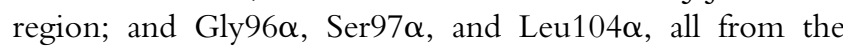
CDR $3 \alpha$ J $\alpha$ segment. Remarkably, Arg33 $\alpha$ that forms the electropositive base of the cavity is unique to $\mathrm{V} \alpha 24$ among all the human $\mathrm{V} \alpha$ genes and is also conserved in mouse $\mathrm{V} \alpha 14$ and in only one other V $\alpha$ family (TRAV7). Similarly, the J $\alpha$ residues Gly96 $\alpha$, Ser97 $\alpha$, and Leu104 $\alpha$ are only found in J $\alpha 18$. The V $\beta$ framework residue Tyr33 $\beta$, adjacent to the $\operatorname{CDR} 1 \beta$, also lines the cavity and is conserved in mouse and human NKT V $\beta$ regions. The NKT15 TCR is virtually identical in structure to NKT12, apart from the amino acid sequence and conformation of its CDR $3 \beta$ regions. These differences include two extra residues encoded by the $\mathrm{D} \beta-\mathrm{N}$ region, thereby introducing a charged, surface-exposed "RDR" motif that forms the tip of CDR $3 \beta$ in the NKT15 TCR. Thus, the hypervariable CDR $3 \beta$ residues that line the cavity of NKT12 include Thr95 $\beta$, Ser96 $\beta$, Ser100 $\beta$, and Tyr101 $\beta$; whereas, in NKT15, the corresponding residues lining the cavity are Ser95 $\beta$, Gly96 $\beta$, Leu $97 \beta$, and Gly $101 \beta$ (Fig. 3, C and D; Table I). Although the positively charged cavity at the Ag-binding interface is conserved between NKT12 and NKT15, in the trigonal crystal form, the entrance to the cavity is occluded by the bulky Tyr103 $\beta(J \beta)$ from the CDR $3 \beta$ loop of NKT15 (Fig. 3 C). Notably, however, this region of the CDR $\beta$ loop is relatively mobile, such that Tyr103 $\beta$ was unresolved in the orthorhombic crystal form. This suggests that Tyr $103 \beta$ could be easily displaced, allowing access of potential ligands to this conserved region (Fig. 3 D). The cavity at the ligand interface could potentially accommodate small polar moieties such as the galactose ring of $\alpha$-GalCer that projects out of the antigen-binding cleft of CD1d $(14,15)$ (Fig. S1, available at http://www.jem.org/ cgi/content/full/jem.20051777/DC1). This would be consistent with a direct interaction between NKT TCRs and the glycosyl head group of $\alpha$-GalCer bound to CD1d, as predicted from many studies and analogous to what has been proposed for CD1b/glycolipid recognition (41). The volume of the cavity would be predicted to vary according to the structure and flexibility of the CDR $3 \beta$ sequences; this might facilitate interaction with other glycolipid head groups.

The CDR3 $\beta$ hypervariable loop modulates antigen specificity Previous studies have shown that mouse V $\beta 8.2^{+}$NKT TCRs can be substituted with $\mathrm{V} \beta 8^{+}$chains from non-NKT cells without loss of binding affinity to $\mathrm{mCD} 1 \mathrm{~d} / \alpha-\mathrm{GalCer}(28)$,
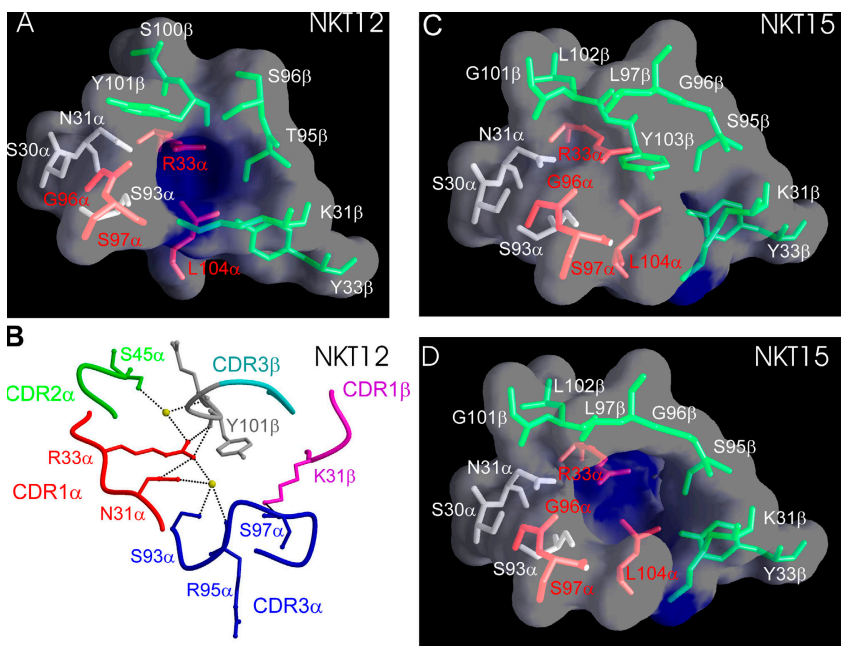

Figure 3. The Ag-binding interface of NTK12 and NKT15 TCRs contains a preformed cavity created by invariant residues of the $\boldsymbol{\alpha}$-chain, a species-conserved residue from the $\boldsymbol{\beta}$-chain and CDR3 $\beta$. (A) NKT12 TCR $\alpha$-chain residues that are conserved between human and mouse are red; $\alpha$-chain residues that differ between these species are gray. The TCR $\beta$-chain residue Tyr $33 \beta$ is conserved across species, whereas the CDR3 $\beta$ residues are divergent between species. $\beta$-chain side chains are green. (B) Close-up of residues forming the putative ligand-binding cavity of the NKT12 binding surface. Residues are labeled according to the single amino acid code. (C) The putative ligand-binding cavity of NKT15 is obstructed by the bulky side chain of residue Tyr $103 \beta$ from CDR3 $\beta$ in the trigonal form of the crystal structure. (D) Tyr $103 \beta$ could not be visualized in the NKT15 TCR crystal comprising the orthorhombic space group. The high mobility of Tyr $103 \beta$ could easily allow displacement of this side chain, exposing the putative Ag-binding cavity. Accordingly, the Tyr $103 \beta$ side chain has been omitted, revealing the cavity.

suggesting that the CDR $3 \beta$ region plays little or no role in NKT cell specificity, at least to this antigen complex. However, the structure of the NKT12 and NKT15 TCRs showed that some CDR $3 \beta$ residues line parts of the cavity at the ligand interface, where they could modulate Ag specificity. We examined the role of CDR $3 \beta$ by assessing how variation in this region affects cross-species reactivity with $\mathrm{CD} 1 \mathrm{~d} / \alpha-$ GalCer. We first measured the affinity of NKT12, NKT15, and NKT18 TCRs for $\alpha$-GalCer complexed to mCD1d and hCD1d using surface plasmon resonance (SPR) (Table S3 and Fig. S2, available at http://www.jem.org/cgi/content/ full/jem.20051777/DC1, and NKT18 not depicted). This allows a direct examination of the impact of the variable CDR $3 \beta$ region on the TCR interaction. The affinity of the NKT12 and NKT15 TCRs was approximately twofold higher for $\mathrm{hCD} 1 \mathrm{~d} / \alpha-\mathrm{GalCer}\left(K_{d(\mathrm{eq})} \sim 10 \mu \mathrm{M}\right)$ versus $\mathrm{mCD} 1 \mathrm{~d} / \alpha$-GalCer $\left(K_{d(\mathrm{eq})} \sim 20 \mu \mathrm{M}\right)$, whereas the affinity of the NKT18 TCR was similar for human and mouse CD1d/ $\alpha$-GalCer $\left(K_{d(\mathrm{eq})} \sim 20 \mu \mathrm{m}\right)$. Although these affinity differences with $\mathrm{mCD} 1 \mathrm{~d} / \alpha-\mathrm{GalCer}$ were small, they were reproducible, indicating a subtle but measurable influence of CDR $3 \beta$ on NKT TCR specificity. 
We next studied the binding of several hybrid TCRs with switched or mutated CDR $3 \beta$ regions (Fig. 4 and Table S4, available at http://www.jem.org/cgi/content/full/ jem.20051777/DC1). The native integrity of these chimeric receptors was intact based on their binding with a conformation-dependent mAb $12 \mathrm{H} 8$ (34) and their behavior by gel filtration and SDS-PAGE (unpublished data). First, we examined the relative roles of the CDR $1 \beta$ and $\operatorname{CDR} 2 \beta$, versus the hypervariable CDR $3 \beta$ residues (encoded by $D \beta-N-J \beta$ gene segments) of NKT15, by swapping the entire NKT15 TCR $\beta$-chain for that of the classical MHC I-restricted TCR LC13 $(36,37)$ (Fig. 4 B). This TCR contains a different V $\beta$ chain (V $\beta 6.2$ or TRBV7-8*03) to NKT15, but uses the same J $\beta$ segment to create the CDR3 $\beta$ loop (TRBD1/D2;
TRBJ2-7*01). The hybrid NKT15 $\alpha /$ LC13 $\beta$ TCR lost virtually all CD $1 \mathrm{~d} / \alpha-$ GalCer binding as measured by both SPR and by failure to inhibit NKT cell staining by CD1d/ $\alpha-G a l-$ Cer tetramer (Fig. 4 B). Although this finding suggests that either CDR $1 \beta$ and/or CDR $2 \beta$ may be crucial for CD $1 d / \alpha-$ GalCer binding, it could also be explained by an incompatibility in the LC13 CDR3 $\beta$ region. Therefore, a chimeric TCR was generated where just the CDR $3 \beta$ loop of NKT15 was replaced with the corresponding loop of LC13 (also encoded by J $\beta$ TRBJ2-7) (Fig. 4 B). This swap shortens the CDR $3 \beta$ loop of NKT15 by three residues and alters the sequence of buried amino acids involved in stabilizing the TCR $\alpha$-chain as well as changing the solvent-exposed residues at the tip of the loop (Table S4). The hybrid TCR had

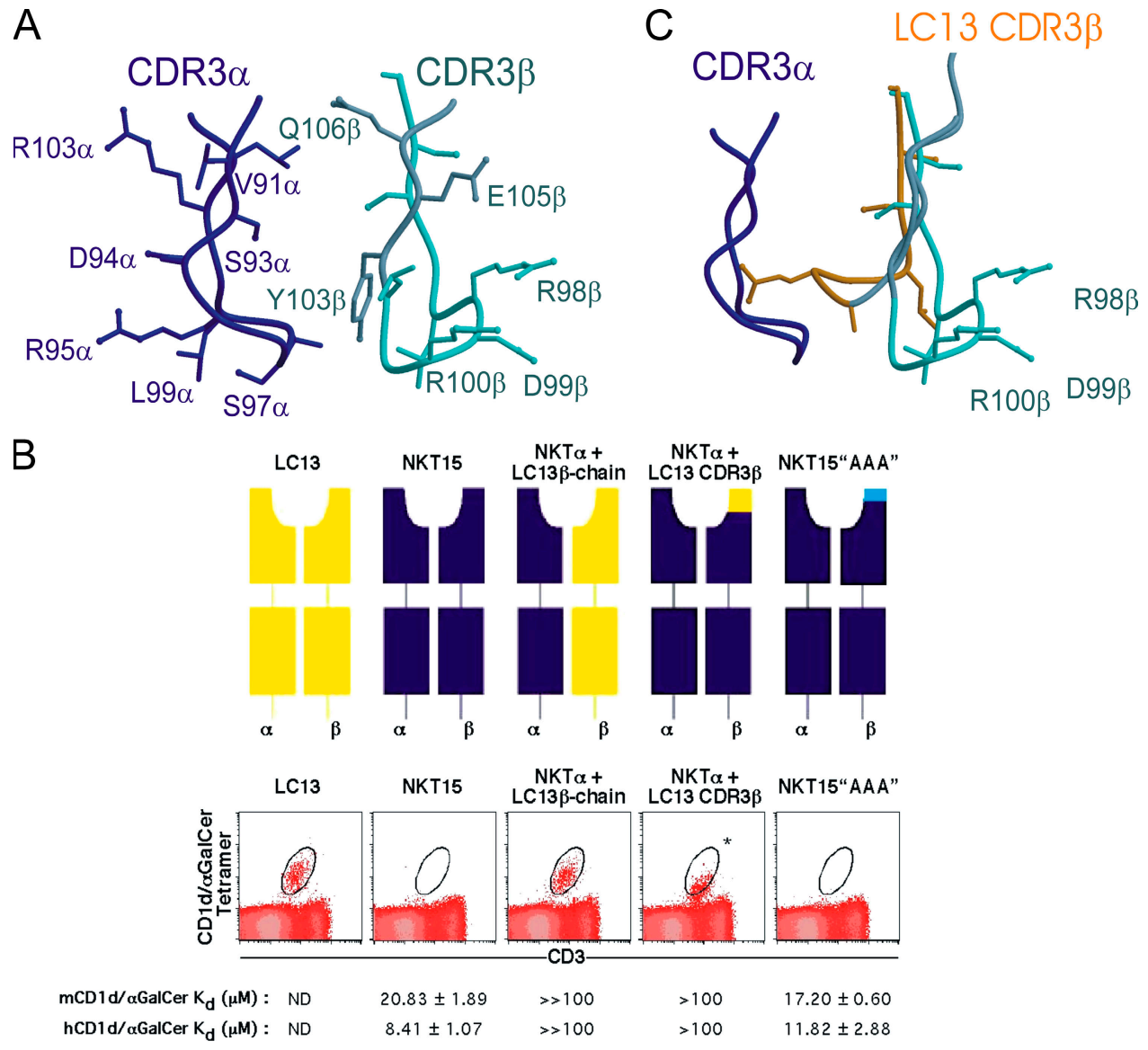

Figure 4. NKT cell receptor CDR3 $\beta$ regions impact on the recognition of CD1d/ $\boldsymbol{\alpha}-$ GalCer. (A) Conformation of the CDR3 loops of the NKT15 TCR revealing the highly exposed "RDR" motif at the tip of the CDR3 $\beta$ loop. (B) Inhibition of NKT cell staining by recombinant wild-type and chimeric NKT TCRs. TCRs comprised LC13 $\alpha \beta$; NKT15 $\alpha \beta$; NKT15 $\alpha-$ chain/LC13 $\beta$-chain; NKT15 $\alpha$-chain/NKT15 $\beta$-chain engrafted with the LC13 CDR3 $\beta$-loop; and NKT15 $\alpha$-chain/NKT15 $\beta$-chain with "RDR" to "AAA" substitution within the CDR3 $\beta$ loop. Graded concentrations of soluble recombinant TCRs were preincubated with phycoerythrin-labeled tetramers of mCD1d $\alpha$-GalCer. These were used to costain mouse thymocyte cells with anti-CD3 mAb and analyzed by flow cytometry. Shown are flow cytometry plots with tetramer-staining after preincubation with
$500 \mu \mathrm{g} / \mathrm{ml}$ TCRs. ${ }^{*}$, the inhibition observed with maximal concentrations of the NKT $\alpha+\mathrm{LC} 13(\mathrm{CDR} 3 \beta)(500 \mu \mathrm{g} / \mathrm{ml})$ was only partial, and equivalent to the inhibition observed with $8 \mu \mathrm{g} / \mathrm{ml}$ (not depicted) of NKT15. The indicated $K_{D}$ values are calculated from SPR studies of TCR binding to immobilized human and mouse CD1d $\alpha$-GalCer (Table S3 and Fig. S2 for NKT12 and NKT15). LC13 is a control TCR from an HLA-B8-restricted, virus-specific CTL; ND, $K_{D}$ not measurable. (C) Superposition of the CDR3 $\beta$ loop of LC13 in the context of the NKT CDR3 $\alpha$ based on the known structure of LC13 (references 36,37 ). The LC13 CDR3 $\beta$ loop is predicted to impact on the conformation of $\operatorname{CDR} 3 \alpha$ and to disrupt access to the putative $\mathrm{Ag}$-binding cavity. 
an $\sim 5-10$-fold lower affinity by SPR measurements than NKT1 5 bound to both human and mouse CD1d/ $\alpha-G a l C e r$. In addition, the hybrid TCR required $\sim 60$-fold higher concentrations than NKT15 to achieve comparable inhibition of staining of mouse NKT cells with $\mathrm{mCD} 1 \mathrm{~d} / \alpha-\mathrm{GalCer}$ tetramers (Fig. 4 B). However, the structures of the LC13 $(36,37)$ and NKT15 TCRs suggested that the orientation of the LC13 CDR $3 \beta$ was likely to sterically impact on the conformation of the NKT15 CDR $3 \alpha$ loop, thereby indirectly affecting the putative binding cavity and disrupting ligand recognition by the hybrid TCR (Fig. 4 C). Notwithstanding these findings, the CDR3 $\beta$ loops of other NKT TCRs show substantial variation $(26,27,42)$, suggesting that sequence variation at the solvent-exposed tips of the CDR3 $\beta$ loops might be well tolerated. To this end, we made a triple alanine mutant in the ${ }^{98} \mathrm{RDR}^{100}$ sequence (encoded by $\mathrm{D} \beta-\mathrm{N}$ ), which is highly solvent accessible and, as such, their mutation is not predicted to affect the conformation of the CDR $3 \alpha$ loop (Fig. 4 A). SPR-binding studies of this "AAA" mutant NKT15 TCR revealed its affinity for both human and mouse CD1d/ $\alpha$-GalCer was comparable to the wild-type NKT15 (Fig. 4 B), indicating these three exposed residues are not critical to the affinity of the interaction. In addition, this hybrid TCR inhibited staining of mouse NKT cells by mCD1d/ $\alpha$-GalCer tetramers at the same concentration as NKT12 and NKT15 TCRs (Fig. 4 B).

Collectively, our data suggest that the function of the CDR $3 \beta$ region is to modulate NKT cell recognition of different glycolipids. Although this modulation of specificity sometimes results in sterically abolishing recognition altogether, as in the substitution of the LC13 CDR $3 \beta$ region in
NKT15, the concept is consistent with a high degree of structural variation being tolerated in this region without loss of affinity.

\section{Cross-species reactivity of NKT cells with CD1d/ $\alpha$-GalCer} Unlike the highly restricted recognition of MHC I molecules by conventional $\alpha \beta$ TCRs, NKT cell TCRs (including NKT12, 15, and 18) show a remarkable cross-species reactivity, implying evolutionary conservation of an important immune specificity and function (33). The invariant TCR $\alpha$-chain from human NKT cells has $54 \%$ sequence identity with its mouse counterpart, whereas the human V $\beta 11$ and mouse V $\beta 8.2$ share $65 \%$ sequence identity. This cross-species identity is particularly marked in the CDR $3 \alpha$ and CDR $1 \alpha$ loops in which $10 / 13$ and $2 / 6$ residues, respectively, are identical between human and mouse sequences (Fig. 5). Moreover, the two identical residues in the CDR $1 \alpha$ are surface exposed. The CDR $3 \alpha$ and CDR $1 \alpha$ residues that are conserved across species form part of an extensive, contiguous surface at the ligand-binding interface of the NKT TCRs (Fig. 5 A). Based on the mode of recognition of $\mathrm{MHC}$-peptide complexes (35), this region of the TCR would be expected to make interactions with the CD1d-glycolipid complex. In addition, the CDR $3 \alpha$ and $\mathrm{CDR} 1 \alpha$ loops make numerous interloop interactions involving residues that are largely conserved between the human and mouse semi-invariant NKT TCRs. These interactions are important in stabilizing the conformation of the CDR loops.

Notably, 0/6 of the amino acids in the human and mouse CDR2 $\alpha$ loop are identical, although the Phe51 (human)

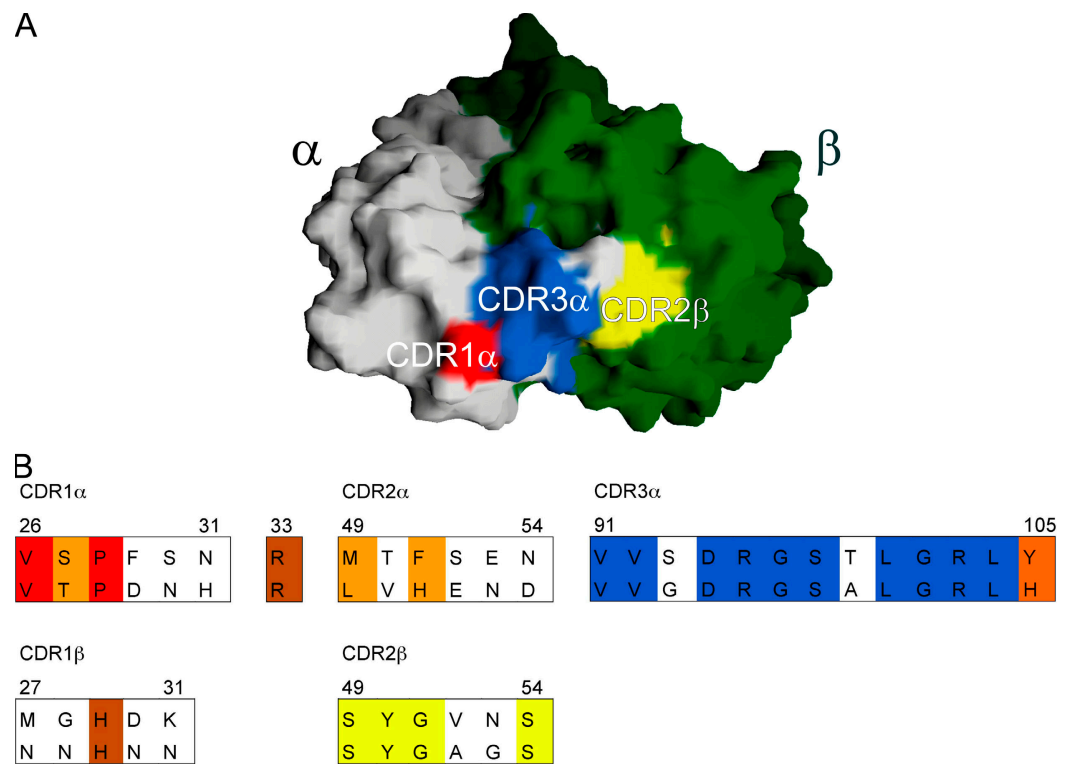

Figure 5. Conserved residues from human and mouse NKT TCR CDR1 $\alpha, \operatorname{CDR} 3 \alpha$, and $\operatorname{CDR} 2 \beta$ loops form a contiguous conserved surface that is adjacent to the putative Ag-binding cavity. The different conserved CDR regions are colored to correspond to the sequence alignment of mouse and human CDR loops. All other conserved and semiconserved residues are brown and orange, respectively, in the alignment and are not shown in the structure. The TcR $\alpha$-chain is white and the TCR $\beta$-chain is green. 
versus His51 (mouse) residues are relatively conserved (Fig. $5 \mathrm{~B})$. This observation is consistent with the natural allelic polymorphism in the mouse V $\alpha 14$ gene (TRAV11*01 vs. TRAV11*02) in which $3 / 7 \operatorname{CDR} 2 \alpha$ residues contain nonconservative substitutions that have minimal impact on TCR affinity for CD1d/ $\alpha-G a l C e r(43)$. These findings suggest a minor role for CDR $2 \alpha$ residues in mediating cross-species CD1d reactivity.

In the TCR $\beta$-chain, only the CDR $2 \beta$ shows significant sequence identity between mouse and human TCRs that

A

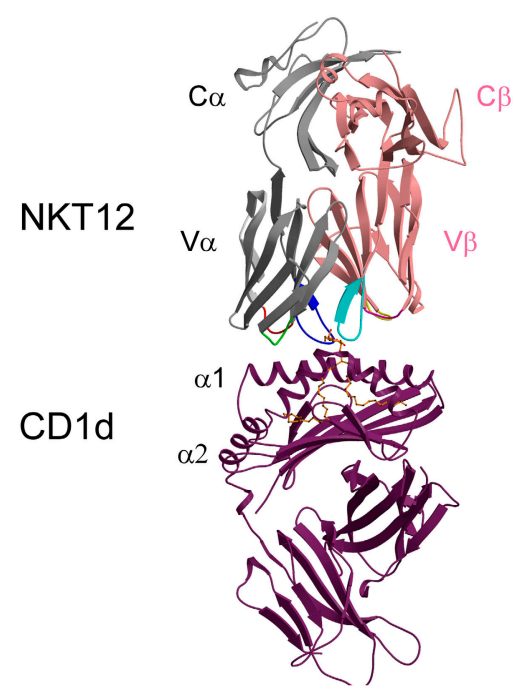

B

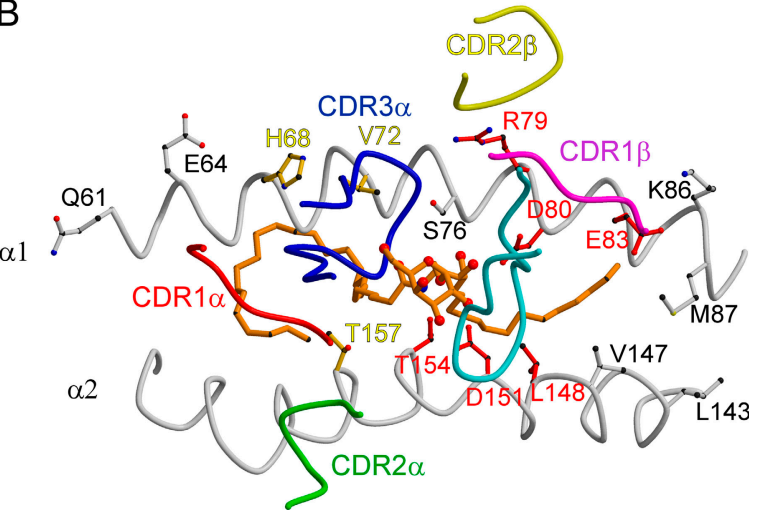

Figure 6. Proposed docking of NKT TCR onto CD1d/ $\alpha$-GalCer. (A) In the model, the NKT12 $\alpha$ and $\beta$ chain are shown in gray and pink, respectively, and the CDR loops are red (CDR1 $\alpha)$, green (CDR2 $\alpha)$, blue (CDR3 $\alpha)$, magenta (CDR1 $\beta$ ), yellow (CDR2 $\beta$ ), and cyan (CDR3 $\beta$ ). $\alpha$-galactosylceramide is shown in orange within the antigen-binding domain of hCD1d (purple). (B) View of the antigen-binding cleft of human CD1d-presenting $\alpha$-GalCer (orange). The CDR footprint of the proposed docking model of NKT12 is shown for reference and the CDR loops are colored as in A. Surface-exposed residues on the $\alpha 1$ and $\alpha 2$ helices of hCD $1 d$ are shown. Residues in red had an impact on NKT activation by mCD1d in the published literature. Residues in white either had no impact or were not investigated. Residues in yellow are those residues likely to be important in the docking of NKT12 onto CD1d/ $\alpha$-galactosylceramide according to our proposed model. share 4/ 6 residues at the tip of this loop, and 4 amino-terminal residues $\left({ }^{45} \mathrm{LIHY}^{48}\right)$ and 5 carboxy-terminal residues $\left({ }^{5} \mathrm{TEKGD}^{59}\right)$ either side of the tip of the loop. Notably, the surface exposed CDR $2 \beta$ loop, and the highly conserved "hot spot" formed by the CDR $3 \alpha$ and $\operatorname{CDR} 1 \alpha$ loops merge to create an even more extensive species-conserved region at the ligand interface (Fig. 5). Accordingly, this region of the TCR is likely to play a crucial role in CD1d-glycolipid interactions by mediating restricted recognition and cross-species reactivity. In contrast with the CDR $2 \beta$ loop, the CDR $1 \beta$ loop is only moderately conserved across human and mouse sequences. However, as outlined earlier, there are five further cross-species conserved residues that line the cavity at the ligand interface of the NKT TCR: Tyr33 $\beta$, Arg33 $\alpha$, Gly96 $\alpha$, Ser97 $\alpha$, and Leu $104 \alpha$.

Collectively, the structures of NKT12 and NKT15 suggest that the species conservation of $\operatorname{CDR} 3 \alpha, \operatorname{CDR} 1 \alpha$, and CDR2 $\beta$ loops creates a contiguous conserved hot spot. It is highly likely that this hot spot and the collection of conserved residues forming the cavity at the ligand-interface are crucial in mediating the reciprocal cross-species reactivity between human and mouse NKT TCRs.

\section{Proposed docking of NKT TCR onto CD1d/ $\alpha-G a I C e r$}

The NKT TCR structure, together with the recently published CD1d/ $\alpha-G a l C e r$ structures and previous mutagenesis experiments, has allowed us to propose a model for the interactions between the NKT TCR and CD1d/ $\alpha-G a l C e r$. For several reasons, the model was based on the LC13-HLA-B8FLR complex. First, we examined all the TCR-MHC-I-p complexes solved to date and the LC13 complex provided the best approximation for docking of the central TCR pocket over the $\alpha$-GalCer head group. Second, like $\alpha-G a l C e r$, the peptide determinant recognized by LC13 is a minimally protruding Ag and is similarly located to the glycosyl head group of $\alpha-$ GalCer. Moreover, LC13 also has a central pocket that accommodates the main side chain of the ligand as proposed for NKT TCRs. Despite the known caveats of any structural estimation, the model provides plausible insight into NKT TCR recognition of $\mathrm{hCD} 1 \mathrm{~d} / \alpha-\mathrm{GalCer}$ and is consistent with several published observations. Thus, in both the mouse and human CD1d molecules, the conserved residues Arg79, Asp80, Glu83, and Asp153 (Asp 151 in hCD1d) are critical for presentation of $\alpha-G a l C e r$ by CD1d (44). Of these amino acids, Arg79 and Asp153, but not Glu83, make interactions with $\alpha$-GalCer $(14,15)$. However, mutagenesis studies suggest that all three can influence recognition by the NKT TCRs $(17,44,45)$, perhaps directly or by affecting the orientation of the $\alpha-G a l C e r$ glycosyl head group. Taking these issues into consideration, the model is consistent with diagonal docking of the NKT TCR over the ligand-binding domain of CD1d (Fig. 6). Because $\alpha-$ GalCer protrudes only minimally from the CD1d cleft, the NKT TCR forms considerable contacts with CD1d. Thus, the CDR $1 \alpha$ and CDR $2 \alpha$ loops are primarily positioned over the $\alpha 2$ helix, interacting with hCD1d residues spanning Trp153-Trp160. The aromatic 
residue Phe51 $\alpha$ (His51 in mouse), located within the CDR $2 \alpha$ loop, could potentially stack neatly between the two bulky aromatic rings of Trp153 and Trp160 of hCD1d. The CDR $1 \beta$ and CDR2 $\beta$ loops docks over the $\alpha 1$ helix of CD1d, interacting with a localized stretch of CD1d residues (75-83). Although CDR2 $\beta$ is located on the periphery, our model suggests that the prominent Tyr48 $\beta$ packs against Ser75 and the aliphatic moiety of Arg79 in CD1d. Moreover, our model suggests a potential salt bridge between Arg79 and Asp30 $\beta$ of the CDR1 $\beta$ loop. This is consistent with a role for Arg79 independent of its interactions with $\alpha-\mathrm{GalCer}$, as an important residue for recognition of CD $1 d / \alpha-G a l C e r$ by many NKT TCRs. Notably, however, substitution of this residue can be tolerated by certain NKT cells indicating a variable contribution of Arg79 contingent upon the nature of the glycolipid Ag (44). The conserved TCR residues Asp $94 \alpha$, Arg95 $\alpha$, and $\operatorname{Arg} 103 \alpha$ are solvent exposed and proximal to the binding interface cavity, where their charged nature provides the potential for complementary electrostatic interactions with one or more of these CD1d residues.

Both the $\operatorname{CDR} 3 \alpha$ and $\operatorname{CDR} 3 \beta$ loops make contact with the galactose moiety of $\alpha$-GalCer in the model; however, the CDR $3 \alpha$ loop is also predicted to interact extensively with the $\alpha 1$ helix (spanning residues $65-72$ ) of CD1d. Thus, the conserved residues within the $\mathrm{CDR} 3 \alpha$ loop are proposed to mediate interactions with conserved residues on CD1d accounting for the inherent bias of this TCR in ligating CD1d. The prominent role of CDR $3 \alpha$ in interacting with CD1d may explain NKT cross-reactivity between mouse and human CD1d, analogous to the way that the CDR $3 \alpha$ loop of the LC13 TCR is suggested to dictate its known alloreactivity (34).

Upon ligation, the surface-exposed galactose of $\alpha-\mathrm{GalCer}$ is "walled" by the CDR $3 \alpha$ and CDR3 $3 \beta$ loops such that the galactose is positioned within the electropositive preformed cavity. The galactose head group of $\alpha-G a l C e r$ is likely to interact with residues lining the pocket, including Asn $31 \alpha$, Arg33 $\alpha$, Gly96 $\alpha$, Ser97 $\alpha$, and Lys31 $\beta$. The role of $\operatorname{Arg} 33 \alpha$ may involve specificity interactions analogous to those observed in the LC13 TCR binding pocket, where His $33 \alpha$ at the base of the pocket makes a water-mediated bond to a critical peptide side-chain from the ligand (37).

Larger Ag headgroups, such as the tri-hexosyl moiety of the glycosphingolipid iGb3 $(7,8)$, are likely to be partially accommodated via movement in the CDR3 loops. This is consistent with the observed plasticity of $\alpha \beta$ TCRs in engaging with pMHC molecules. We predict that the flexible CDR3 $\beta$ loop will allow modulation of NKT cell recognition of different glycolipids. Therefore, the extent of the preformed cavity volume is likely to change, depending on the position of the CDR $3 \beta$ loop. This is consistent with a high degree of structural variation being tolerated in this region without loss of affinity to ligands such as $\alpha-$ GalCer.

\section{DISCUSSION}

NKT cells straddle the roles of both innate and adaptive cellular immune responses (46). They respond rapidly upon antigen recognition by their semi-invariant TCR, producing a variety of cytokines that can regulate tumor immunity, autoimmunity, and allergy and can orchestrate protective responses to infectious agents $(2,47-49)$. Despite expressing a semi-invariant TCR, NKT cells are reported to be selected or activated by different glycolipid molecules such as the marine sponge-derived $\alpha$-GalCer (6), a phosphoethanolamine (50), PIM4 (11), $\alpha$-glycuronosyl-ceramides (8-10, 51, 52), sulfated variants thereof (10), a tumor-derived ganglioside GD3 (31), self-antigens including some forms of $\beta$-galactosylceramide $(53,54)$, and isoglobotrihexosylceramide (iGb3) (7). This capacity to recognize a variety of foreign and selfderived glycolipid Ags reflects the increasingly diverse functional roles ascribed to NKT cells (47-49) and highlights the need for a structural explanation as to how the semi-invariant NKT TCR can achieve such a diversity of recognition. Abundant evidence suggests that the glycosyl head group of the glycolipid sugar moiety is a critical determinant recognized by the NKT TCR (14-16, 29, 44, 45, 55, 56). Thus, the NKT TCR binds efficiently to CD1d complexed with $\alpha-$ GalCer but not with $\beta-$ GalCer containing similar sphingosine and acyl chains (56), consistent with the lipid chains being buried in the Ag-binding cavity, whereas the glycosyl head group protrudes out of the cleft $(14,15)$. It is notable that the small target created by the polar head of $\alpha-\mathrm{GalCer}$ induces a highly selected "immunodominant" $\alpha \beta$ TCR repertoire. This bias is reminiscent of the highly restricted CTL repertoires toward minimally exposed $(36,57,58)$ or highly unusual viral determinants (59-61).

These observations would be consistent with the cavity at the ligand interface of the NKT12 and NKT15 TCRs acting as a preformed $\mathrm{Ag}$ pocket. The structures of CD1d/ $\alpha \mathrm{GalCer}$ have led to speculation that the CDR $3 \alpha$ of the NKT TCR would be placed over the galactose ring (14). This mode of interaction fits the idea that the cavity might envelope the polar glycosyl head group of $\alpha-G a l C e r$ and some related antigens. Supporting this interpretation, the walls of the cavity are formed from unique amino acids present in the $\mathrm{V} \alpha$ domain $(\mathrm{CDR} 1 \alpha$ and $\operatorname{Arg} 33 \alpha)$ and $\operatorname{CDR} 3 \alpha$ regions of the invariant TCR $\alpha$-chain. Moreover, these regions are highly conserved between mouse and human NKT TCRs that are functionally cross-reactive (62). In addition, CDR $1 \beta$ and CDR $3 \beta$ residues also contribute to the cavity wall, providing a mechanism by which the CDR3 $\beta$ could modulate Ag specificity. Many studies have reported heterogeneous CDR3 $\beta$ usage by NKT cells, suggesting that these loops do not play a key role in NKT cell recognition (25-28). However, our data indicate that not all CDR $3 \beta$ sequences support recognition of CD1d-glycolipid complexes and this is probably the result of steric hindrance by some CDR $3 \beta$ loops that obstruct the cavity interface and/or interfere with the conformation of the highly conserved CDR $3 \alpha$ loops.

The binding kinetics and affinities of the human NKT12, NKT15, and NKT18 TCRs for hCD1d/ $\alpha-$ GalCer are typical of conventional $\alpha \beta$ TCR-MHCp interactions with $\mathrm{K}_{\mathrm{D}}$ values of $\sim 8-20 \mu \mathrm{M}$. This contrasts with the high affinity 
binding of recombinant mouse NKT TCRs, where the $\mathrm{K}_{\mathrm{D}}$ values are reported to be $\sim 0.1-0.3 \mu \mathrm{M}(28,45)$. These differences presumably reflect species variability despite the remarkable reciprocal cross-reactivity of human and mouse NKT cells. This cross-reactivity correlates with a conserved hot spot at the NKT TCR interface that comprises a contiguous surface suitable for interacting with CD1d-glycolipid complexes. Additional conserved residues forming the cavity at the ligand interface are also likely to contribute to the reciprocal cross-species reactivity. Despite the cross-species interactions, the glycosyl head group of $\alpha-G a l C e r$ is shifted by up to $3 \AA$ between the mouse and human structures, which is likely to impact on the recognition of the galactose moiety itself (63). Human CD1d has a tryptophan residue at position 153 that pushes the galactose head group away, whereas, in mouse, the equivalent amino acid (position 155) is a much smaller glycine residue $(14,15)$. The previously reported lack of temperature dependence in the binding affinity of mouse NKT TCRs with CD1d- $\alpha$ GalCer suggests a rigid "lock and key" mode of binding $(28,56)$. However, the cross-reactivity of human and mouse NKT TCR for CD1d- $\alpha-$ GalCer implies that NKT TCR recognition has considerable structural plasticity more typical of $\alpha \beta$ TCR-MHC-I interactions and potentially important in the recognition of different glycolipid antigens.

How can NKT cells, with a semi-invariant TCR, recognize a diversity of glycolipid antigens with structurally distinct carbohydrate head groups? Although this can only be definitively answered with direct structural studies, the recently defined $\alpha$-glucuronosylceramides $(8-10,51,52)$ are structurally very similar to $\alpha$-GalCer and $\alpha$-glucosylceramide and thus conceivably would fit into the same TCR cavity. It is also possible, or even likely, that only a minor subset of fresh human NKT cells recognize some of these more recently defined antigens. For example, $<10 \%$ of NKT cells were labeled by PIM4-loaded CD1d tetramers (11) and the labeling was 10-100-fold weaker than for $\alpha$-GalCer-loaded CD1d tetramers. Similarly, although in mice most NKT cells depend on iGb3 for thymic selection (7), it is not proven that iGb3 is a key selecting ligand for human NKT cells (64). Moreover, given that mouse NKT cells do not stain with CD1d/iGb3 tetramers (7), their affinity for NKT TCRs is likely to be very low, suggesting that the tri-hexosyl head group of this Ag might be poorly recognized in comparison to the galactosyl head group of $\alpha-\mathrm{GalCer}$. Furthermore, the extent to which fresh human NKT cells recognize other glycolipid ligands such as GD3 (31) and phosphoethanolamine (50) is unknown. Notwithstanding these concerns, it is not inconceivable that different sugar groups could be accommodated within the pocket by a degree of plasticity in the CDR 3 loops and in particular the CDR $3 \beta$ loop, which was shown to exhibit a degree of flexibility in our study.

Collectively, our findings suggest a basis for the semiinvariant nature of NKT TCRs in which highly conserved residues in the $\alpha$ - and $\beta$-chains of the TCR contribute to binding of glycolipid head groups through a discrete cavity at the ligand interface. Other conserved features of the NKT TCR appear to play a role in CD1d binding, whereas plasticity of antigen recognition is preserved through variation in CDR $3 \beta$ loops and the intrinsic adaptability of other CDR loops at the ligand interface. Furthermore, our proposed model of the complex suggests that the CDR $3 \alpha$ loop plays a prominent role in determining Ag specificity as well as dictating the observed cross-species reactivity via interactions with CD1d. It will be intriguing to visualize this plasticity in complexes of NKT TCRs with a variety of CD1d/glycolipid antigens and to correlate the modes of interaction with functional diversity in NKT cells.

\section{MATERIALS AND METHODS}

Protein expression, refolding, and purification. cDNAs encoding NKT cell receptors and CD1d were derived as described in the Supplemental Materials and methods. Inclusion body protein of the NKT TCR $\alpha$ and NKT TCR $\beta$ chains were prepared essentially as described previously (36, 37, 65). $64 \mathrm{mg}$ TCR $\alpha$ and $32 \mathrm{mg}$ TCR $\beta$ inclusion body proteins were thawed, pulsed with $1 \mathrm{mM}$ DTT, combined, and injected into $800 \mathrm{ml}$ of

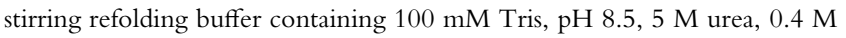
arginine, $0.5 \mathrm{mM}$ oxidized glutathione, $5 \mathrm{mM}$ reduced glutathione, $2 \mathrm{mM}$ EDTA, $0.2 \mathrm{mM}$ PMSF, and $1 \mu \mathrm{g} / \mathrm{ml}$ Pepstatin A at $4^{\circ} \mathrm{C}$. Equal amounts of the NKT TCR $\alpha$ and NKT TCR $\beta$ chain inclusion body proteins were added $16 \mathrm{~h}$ later. After $24 \mathrm{~h}$, refolded protein was dialyzed against $10 \mathrm{mM}$ Tris- $\mathrm{HCl}, 0.1 \mathrm{M}$ urea, $\mathrm{pH}$, and subsequently against $10 \mathrm{mM}$ Tris- $\mathrm{HCl}$. Dialyzed protein was captured on a column containing DEAE Sepharose Fast Flow (GE Healthcare), and eluted with $10 \mathrm{mM}$ Tris-HCl, $200 \mathrm{mM}$ $\mathrm{NaCl}$. Eluted NKT TCR was concentrated and loaded unto a HiLoad Superdex 75 pg gel filtration column (GE Healthcare) in the presence of $10 \mathrm{mM}$ Tris- $\mathrm{HCl}, 150 \mathrm{mM} \mathrm{NaCl}$. Fractions containing the TCR were pooled and purified further on a Mono-Q column (GE Healthcare). Peak fractions were pooled and concentrated before one more purification by gel filtration as described earlier in this paragraph. Peak fractions were concentrated to $10-20 \mathrm{mg} / \mathrm{ml}$ and were used subsequently in crystal trials.

Crystallization. Rod-shaped crystals of the NKT TCRs were grown at $12 \mathrm{mg} / \mathrm{ml}$ by the hanging drop vapor diffusion technique and at room temperature. NKT12 crystals grew in 18\% PEG 3350, $0.1 \mathrm{M}$ cacodylate, $\mathrm{pH}$ 6.3, 0.2 M lithium chloride, and NKT15 crystals grew in 9\% PEG 3350, $0.1 \mathrm{M}$ cacodylate, $\mathrm{pH}$ 6.4, $0.2 \mathrm{M}$ ammonium acetate. The crystals belong to space group $\mathrm{C} 222_{1}$ and the unit cell dimensions were consistent with one molecule per asymmetric unit (Table II). NKT15 crystals were also grown in $0.2 \mathrm{M}$ sodium sulfate. $20 \% \mathrm{PEG} 3350, \mathrm{pH}$ 6.6. These crystals belong to space group $\mathrm{P}_{2}$, with unit cell dimensions consistent with two molecules per asymmetric unit (Table II).

Structure determination and refinement. The crystals were flash frozen before data collection using up to $15 \%$ glycerol as the cryoprotectant. The data were processed and scaled using the HKL package. Datasets of 2.2, 2.4, and 2.6 A resolution were collected at the BioCars beamline using a Quantum $4 \mathrm{CCD}$ detector (Table II). The crystal structures were solved using the molecular replacement method, as implemented in MOLREP (66), using the unliganded LC13 (37) structure as the search model, where the LC13 CDR loops were initially removed and all other nonidentical residues were mutated to alanine. Unbiased features in the initial electron density map confirmed the correctness of the molecular replacement solution. The progress of refinement was monitored by the $R_{\text {free }}$ value with neither a sigma, nor a low resolution cut off being applied to the data. Initially, the structures were refined using rigid-body fitting of the individual domains followed by the simulated-annealing protocol implemented in CNS (version 1.0) (67). Later, translation, libration, and screw-rotation displacement (TLS) refinement was performed using REFMAC (68). Refinement was interspersed 
with rounds of model building using the program "O" (69). Tightly restrained individual B-factor refinement was used, and bulk solvent corrections were applied to the data set. Water molecules were included in the model if they were within hydrogen-bonding distance to chemically reasonable groups, appeared in $F_{\mathrm{o}}-F_{\mathrm{c}}$ maps contoured at $3.5 \sigma$, and had a B-factor of $<60 \AA^{2}$. The structures have been deposited in the PDB (accession nos. 2EYR, 2EYS, 2EYT).

Biotinylation of CD1d and loading with $\alpha$-GalCer. Biotinylated CD1d was mixed with $\alpha$-GalCer at a molar ratio of 1:3 (protein:lipid) at room temperature overnight. Loaded CD1d protein was then purified from free $\alpha-\mathrm{GalCer}$ and buffer exchanged into $10 \mathrm{mM}$ Hepes-HCl, $\mathrm{pH}$ 7.4, 150 $\mathrm{mM} \mathrm{NaCl}$, and $0.005 \%$ surfactant P20 using a HiLoad Superdex 200 pg gel filtration column (GE Healthcare). Protein quality was monitored by its gel filtration profile and mobility on SDS-PAGE.

SPR binding studies. All SPR experiments were conducted at $25^{\circ} \mathrm{C}$ on a Biacore 3000 instrument using HBS buffer $(10 \mathrm{mM}$ Hepes- $\mathrm{HCl}$, pH 7.4, $150 \mathrm{mM} \mathrm{NaCl}$, and $0.005 \%$ surfactant P20 supplied by the manufacturer) supplemented with $1 \%$ BSA. Approximately 2,000-3,000 RU of $\alpha-\mathrm{Gal}-$ Cer-loaded human and mouse CD1d was immobilized onto streptavidincoupled sensor chip (BiaCore). Corresponding levels of "unloaded" CD1d were also immobilized to act as controls. Equilibrium affinity was determined by injecting increasing concentrations of NKT TCR over all flow cells at $5 \mu \mathrm{l} / \mathrm{min}$ for $3 \mathrm{~min}$. The final response was calculated by subtracting the response of the "unloaded" CD1d surface from the $\alpha$-GalCer CD1d surface. BIAevaluation version 3.1 (Biacore $\mathrm{AB}$ ) was used to fit the equilibrium data.

CD1d/ $\alpha$-GalCer tetramer inhibition assay and flow cytometry. Anti-CD3-FITC (clone 145-2C11) was purchased from BD Biosciences. Fc-receptor block (anti-CD16/CD32, clone 2.4G2) was added to all staining cocktails. Mouse CD1d tetramer loaded with $\alpha-$ GalCer was produced as described previously (70). CD1d/ $\alpha-G a l C e r$ tetramer was incubated with serially diluted (twofold dilutions from $500 \mu \mathrm{g} / \mathrm{ml}$ to $4 \mu \mathrm{g} / \mathrm{ml}$ ) soluble human NKT cell TCR or an irrelevant TCR (LC13) control. Thymic cell suspensions were made by gently grinding the organ between the frosted ends of glass microscope slides in ice-cold PBS containing 2\% FCS (FACS buffer). Cell suspensions were passed through $100 \mu \mathrm{m}$ mesh before antibody staining. Equivalent inhibition of staining of thymocytes with CD1d/ $\alpha$-GalCer tetramers was observed with NKT12, NKT15, NKT18, and NKT15'AAA' TCRs, and inhibition with these NKT TCRs was diminished equally upon dilution. Thymocytes were stained with anti-CD3 mAb, washed with FACS buffer, and stained with the CD1d/ $\alpha-G a l C e r$ tetramer-TCR mixtures. Cells were washed with FACS buffer to remove any unbound CD1d/ $\alpha-$ GalCer tetramer and analyzed by flow cytometry using a FACScalibur (Becton Dickinson) and analyzed using CELLQuest software (Becton Dickinson).

Modelling of the NKT TCR-CD1d- $\alpha-G a l C e r$ complex. The docking of NKT12 onto hCD1d was approximated in the following way. The MHC of each of the MHC-peptide-TCR complex structures available in the PDB was aligned onto the CD1d antigen-binding domain (residues 61-86 and 139-171). The TCRs from each of the complexes were examined for clashes with the helices of hCD1d and the $\alpha-G a l C e r$. The TCR with the best fit over CD1d/ $\alpha-$ GalCer was LC13 (PDB code: $1 \mathrm{MI} 5$ ) and so the $\mathrm{C} \alpha$ domain of LC13 was used to superpose NKT12 in the final CD1d- $\alpha-G a l C e r-$ NKT12 model. NKT12 was adjusted manually using the program "O" to promote a better fit for our proposed model.

Online supplemental material. Supplemental Materials and methods for cDNA cloning of NKT TCRs and CD1d are provided. Table S1 provides contacts at the $\mathrm{V} \alpha-\mathrm{V} \beta$ interface of NKT12 and the genetic origin of TCR residues. Table S2 describes the Phi psi torsion angles of CDR1 and CDR2 in NKT12. Table S3 describes the dissociation constants of natural and mutated NKT TCRs with CD1d/ $\alpha-$ GalCer. Table S4 gives the amino acid sequences of CDR $3 \beta$ residues in natural and mutated NKT TCRs. Fig. S1 models the Ag-binding cavity of the NKT TCR to demonstrate how this can accommodate the galactose head group of $\alpha$-GalCer. Fig. S2 shows the SPR sensorgrams and affinity estimations of NKT12 binding to immobilized hCD1d-GalCer and mCD1d-GalCer. Online supplemental material is available at http://www.jem.org/cgi/content/full/jem.20051777/DC1.

We thank S. Berzins for help in generating the NKT cell lines. We thank the staff at BioCARS and the Australian Synchrotron Research Program for assistance.

J. Rossjohn is supported by an Australian Research Council Professorial Fellowship and N.A. Borg, T. Beddoe, D.I. Godfrey, and M.J. Smyth are supported by National Health and Medical Research Council (NHMRC) Research Fellowships. G.S. Besra, a Lister-Institute-Jenner Research Fellow, acknowledges support from The Medical Research Council (grant nos. G9901077 and G0400421) and The Wellcome Trust (grant no. 072021/Z/03/Z). This work was also supported in part by the NHMRC Australia, the Australian Research Council, the Cancer Council Victoria, and the Roche Organ Transplantation Research Foundation.

The authors have no conflicting financial interests.

Submitted: 1 September 2005

Accepted: 1 February 2006

\section{REFERENCES}

1. Ulrichs, T., and S.A. Porcelli. 2000. CD1 proteins: targets of T cell recognition in innate and adaptive immunity. Rev. Immunogenet. 2:416-432.

2. Brigl, M., and M.B. Brenner. 2004. CD1: antigen presentation and T cell function. Annu. Rev. Immunol. 22:817-890.

3. Kobayashi, E., K. Motoki, T. Uchida, H. Fukushima, and Y. Koezuka. 1995. Krn7000, a novel immunomodulator, and its antitumor activities. Oncol. Res. 7:529-534.

4. Hansen, D.S., M.A. Siomos, L. Buckingham, A.A. Scalzo, and L. Schofield. 2003. Regulation of murine cerebral malaria pathogenesis by CD1d-restricted NKT cells and the natural killer complex. Immunity. 18:391-402.

5. Schofield, L., M.J. McConville, D. Hansen, A.S. Campbell, B. FraserReid, M.J. Grusby, and S.D. Tachado. 1999. CD1d-restricted immunoglobulin $\mathrm{G}$ formation to GPI-anchored antigens mediated by NKT cells. Science. 283:225-229.

6. Kawano, T., J.Q. Cui, Y. Koezuka, I. Toura, Y. Kaneko, K. Motoki, H. Ueno, R. Nakagawa, H. Sato, E. Kondo, et al. 1997. CD1d-restricted and TCR-mediated activation of V $\alpha 14$ NKT cells by glycosylceramides. Science. 278:1626-1629.

7. Zhou, D., J. Mattner, C. Cantu III, N. Schrantz, N. Yin, Y. Gao, Y. Sagiv, K. Hudspeth, Y.P. Wu, T. Yamashita, et al. 2004. Lysosomal glycosphingolipid recognition by NKT cells. Science. 306:1786-1789.

8. Mattner, J., K.L. Debord, N. Ismail, R.D. Goff, C. Cantu III, D. Zhou, P. Saint-Mezard, V. Wang, Y. Gao, N. Yin, et al. 2005. Exogenous and endogenous glycolipid antigens activate NKT cells during microbial infections. Nature. 434:525-529.

9. Kinjo, Y., D. Wu, G. Kim, G.W. Xing, M.A. Poles, D.D. Ho, M. Tsuji, K. Kawahara, C.H. Wong, and M. Kronenberg. 2005. Recognition of bacterial glycosphingolipids by natural killer $\mathrm{T}$ cells. Nature. 434:520-525.

10. Wu, D., G.W. Xing, M.A. Poles, A. Horowitz, Y. Kinjo, B. Sullivan, V. Bodmer-Narkevitch, O. Plettenburg, M. Kronenberg, M. Tsuji, et al. 2005. Bacterial glycolipids and analogs as antigens for CD1d-restricted NKT cells. Proc. Natl. Acad. Sci. USA. 102:1351-1356.

11. Fischer, K., E. Scotet, M. Niemeyer, H. Koebernick, J. Zerrahn, S Maillet, R. Hurwitz, M. Kursar, M. Bonneville, S.H. Kaufmann, and U.E. Schaible. 2004. Mycobacterial phosphatidylinositol mannoside is a natural antigen for CD1d-restricted T cells. Proc. Natl. Acad. Sci. USA. 101:10685-10690.

12. Kawano, T., Y. Tanaka, E. Shimizu, Y. Kaneko, N. Kamata, H. Sato, H. Osada, S. Sekiya, T. Nakayama, and M. Taniguchi. 1999. A novel recognition motif of human NKT antigen receptor for a glycolipid ligand. Int. Immunol. 11:881-887.

13. Burdin, N., L. Brossay, Y. Koezuka, S.T. Smiley, M.J. Grusby, M. Gui, M. Taniguchi, K. Hayakawa, and M. Kronenberg. 1998. Selective ability 
of mouse CD1 to present glycolipids: $\alpha$-galactosylceramide specifically stimulates V $\alpha 14^{+}$NK T lymphocytes. J. Immunol. 161:3271-3281.

14. Zajonc, D.M., C. Cantu, J. Mattner, D. Zhou, P.B. Savage, A. Bendelac, I.A. Wilson, and L.D. Teyton. 2005. Structure and function of a potent agonist for the semi-invariant natural killer $\mathrm{T}$ cell receptor. Nat. Immunol. 6:810-818.

15. Koch, M., V.S. Stronge, D. Shepherd, S.D. Gadola, B. Mathew, G. Ritter, A.R. Fersht, G.S. Besra, R.R. Schmidt, E.Y. Jones, and V. Cerundolo. 2005. The crystal structure of human CD1d with and without $\alpha$-galactosylceramide. Nat. Immunol. 6:819-826.

16. Grant, E.P., M. Degano, J.P. Rosat, S. Stenger, R.L. Modlin, I.A. Wilson, S.A. Porcelli, and M.B. Brenner. 1999. Molecular recognition of lipid antigens by T cell receptors. J. Exp. Med. 189:195-205.

17. Porcelli, S., C.E. Yockey, M.B. Brenner, and S.P. Balk. 1993. Analysis of T cell antigen receptor (TCR) expression by human peripheral blood CD4-8- $\alpha / \beta$ T cells demonstrates preferential use of several $\mathrm{V} \beta$ genes and an invariant TCR $\alpha$ chain. J. Exp. Med. 178:1-16.

18. Lantz, O., and A. Bendelac. 1994. An invariant T cell receptor $\alpha$ chain is used by a unique subset of major histocompatibility complex class I-specific $\mathrm{CD}^{+}$and $\mathrm{CD} 4^{-} 8^{-} \mathrm{T}$ cells in mice and humans. J. Exp. Med. 180:1097-1106.

19. Dellabona, P., E. Padovan, G. Casorati, M. Brockhaus, and A. Lanzavecchia. 1994. An invariant $\mathrm{V} \alpha$ 24-J $\alpha \mathrm{Q} / \mathrm{V} \beta 11 \mathrm{~T}$ cell receptor is expressed in all individuals by clonally expanded $\mathrm{CD} 4^{-} 8^{-} \mathrm{T}$ cells. J. Exp. Med. 180:1171-1176.

20. Lefranc, M.P. 2001. IMGT, the international ImMunoGeneTics database. Nucleic Acids Res. 29:207-209.

21. Emoto, M., Y. Emoto, and S.H. Kaufmann. 1995. IL-4 producing $\mathrm{CD} 4{ }^{+}$TCR $\alpha \beta$ int liver lymphocytes: influence of thymus, $\beta 2$-microglobulin and NK 1.1 expression. Int. Immunol. 7:1729-1739.

22. Bendelac, A., M.N. Rivera, S.H. Park, and J.H. Roark. 1997. Mouse CD1-specific NK1 T cells: development, specificity, and function. Annu. Rev. Immunol. 15:535-562.

23. Cui, J., T. Shin, T. Kawano, H. Sato, E. Kondo, I. Toura, Y. Kaneko, H. Koseki, M. Kanno, and M. Taniguchi. 1997. Requirement for V $\alpha 14$ NKT cells in IL-12-mediated rejection of tumors. Science. 278:1623-1626.

24. Schumann, J., R.B. Voyle, B.Y. Wei, and H.R. MacDonald. 2003. Cutting edge: influence of the TCR V $\beta$ domain on the avidity of CD1d: $\alpha$-galactosylceramide binding by invariant V $\alpha 14$ NKT cells. J. Immunol. 170:5815-5819.

25. Matsuda, J.L., L. Gapin, N. Fazilleau, K. Warren, O.V. Naidenko, and M. Kronenberg. 2001. Natural killer T cells reactive to a single glycolipid exhibit a highly diverse $\mathrm{T}$ cell receptor $\beta$ repertoire and small clone size. Proc. Natl. Acad. Sci. USA. 98:12636-12641.

26. Ronet, C., M. Mempel, N. Thieblemont, A. Lehuen, P. Kourilsky, and G. Gachelin. 2001. Role of the complementarity-determining region 3 (CDR3) of the TCR- $\beta$ chains associated with the V $\alpha 14$ semi-invariant TCR $\alpha$-chain in the selection of CD4(+) NK T cells. J. Immunol. 166:1755-1762.

27. Porcelli, S., D. Gerdes, A.M. Fertig, and S.P. Balk. 1996. Human T cells expressing an invariant $\mathrm{V} \alpha 24-\mathrm{J} \alpha \mathrm{Q}$ TCR $\alpha$ are $\mathrm{CD} 4^{-}$and heterogeneous with respect to TCR $\beta$ expression. Hum. Immunol. 48:63-67.

28. Cantu, C., III, K. Benlagha, P.B. Savage, A. Bendelac, and L. Teyton. 2003. The paradox of immune molecular recognition of $\alpha$-galactosylceramide: low affinity, low specificity for CD1d, high affinity for $\alpha \beta$ TCRs. J. Immunol. 170:4673-4682.

29. Burdin, N., L. Brossay, M. Degano, H. Iijima, M. Gui, I.A. Wilson, and M. Kronenberg. 2000. Structural requirements for antigen presentation by mouse CD 1. Proc. Natl. Acad. Sci. USA. 97:10156-10161.

30. Gui, M., J. Li, L.J. Wen, R.R. Hardy, and K. Hayakawa. 2001. TCR $\beta$ chain influences but does not solely control autoreactivity of V $\alpha 14 \mathrm{~J} 281$ T cells. J. Immunol. 167:6239-6246.

31. Wu, D.Y., N.H. Segal, S. Sidobre, M. Kronenberg, and P.B. Chapman. 2003. Cross-presentation of disialoganglioside GD3 to natural killer T cells. J. Exp. Med. 198:173-181.

32. Benlagha, K., A. Weiss, A. Beavis, L. Teyton, and A. Bendelac. 2000 In vivo identification of glycolipid antigen-specific $T$ cells using fluorescent CD1d tetramers. J. Exp. Med. 191:1895-1903.
33. Brossay, L., M. Chioda, N. Burdin, Y. Koezuka, G. Casorati, P. Dellabona, and M. Kronenberg. 1998. CD1d-mediated recognition of an $\alpha$-galactosylceramide by natural killer $\mathrm{T}$ cells is highly conserved through mammalian evolution. J. Exp. Med. 188:1521-1528.

34. Borg, N.A., L.K. Ely, T. Beddoe, W.A. Macdonald, H.H. Reid, C.S. Clements, A.W. Purcell, L. Kjer-Nielsen, J.J. Miles, S.R. Burrows, et al. 2005. The CDR3 regions of an immunodominant $T$ cell receptor dictate the 'energetic landscape' of peptide-MHC recognition. Nat. Immunol. 6:171-180.

35. Rudolph, M.G., and I.A. Wilson. 2002. The specificity of TCR/pMHC interaction. Curr. Opin. Immunol. 14:52-65.

36. Kjer-Nielsen, L., C.S. Clements, A.W. Purcell, A.G. Brooks, J.C. Whisstock, S.R. Burrows, J. McCluskey, and J. Rossjohn. 2003. A structural basis for the selection of dominant $\alpha \beta \mathrm{T}$ cell receptors in antiviral immunity. Immunity. 18:53-64.

37. Kjer-Nielsen, L., C.S. Clements, A.G. Brooks, A.W. Purcell, J. McCluskey, and J. Rossjohn. 2002. The $1.5 \AA$ crystal structure of a highly selected antiviral $\mathrm{T}$ cell receptor provides evidence for a structural basis of immunodominance. Structure. 10:1521-1532.

38. Garcia, K.C., M. Degano, L.R. Pease, M. Huang, P.A. Peterson, L. Teyton, and I.A. Wilson. 1998. Structural basis of plasticity in T cell receptor recognition of a self peptide-MHC antigen. Science. 279: 1166-1172.

39. Garcia, K.C., M. Degano, R.L. Stanfield, A. Brunmark, M.R. Jackson, P.A. Peterson, L. Teyton, and I.A. Wilson. 1996. An $\alpha \beta$ T cell receptor structure at $2.5 \AA$ and its orientation in the TCR-MHC complex. Science. 274:209-219.

40. Al-Lazikani, B., A.M. Lesk, and C. Chothia. 2000. Canonical structures for the hypervariable regions of $\mathrm{T}$ cell $\alpha \beta$ receptors. J. Mol. Biol. 295:979-995.

41. Grant, E.P., E.M. Beckman, S.M. Behar, M. Degano, D. Frederique, G.S. Besra, I.A. Wilson, S.A. Porcelli, S.T. Furlong, and M.B. Brenner. 2002. Fine specificity of TCR complementarity-determining region residues and lipid antigen hydrophilic moieties in the recognition of a CD1-lipid complex. J. Immunol. 168:3933-3940.

42. Exley, M., J. Garcia, S.P. Balk, and S. Porcelli. 1997. Requirements for CD1d recognition by human invariant $\mathrm{V} \alpha 24^{+} \mathrm{CD} 4^{-} \mathrm{CD} 8^{-} \mathrm{T}$ cells. J. Exp. Med. 186:109-120.

43. Sim, B.C., K. Holmberg, S. Sidobre, O. Naidenko, N. Niederberger, S.D. Marine, M. Kronenberg, and N.R. Gascoigne. 2003. Surprisingly minor influence of TRAV11 (Vo14) polymorphism on NK T-receptor $\mathrm{mCD} 1 / \alpha$-galactosylceramide binding kinetics. Immunogenetics. $54: 874-883$.

44. Kamada, N., H. Iijima, K. Kimura, M. Harada, E. Shimizu, S Motohashi, T. Kawano, H. Shinkai, T. Nakayama, T. Sakai, et al. 2001 Crucial amino acid residues of mouse CD1d for glycolipid ligand presentation to V $114 \mathrm{NKT}$ cells. Int. Immunol. 13:853-861.

45. Sidobre, S., O.V. Naidenko, B.C. Sim, N.R.J. Gascoigne, K.C. Garcia, and M. Kronenberg. 2002. The V $\alpha 14$ NKT cell TCR exhibits highaffinity binding to a glycolipid/CD1d complex. J. Immunol. 169: 1340-1348.

46. Taniguchi, M., K. Seino, and T. Nakayama. 2003. The NKT cell system: bridging innate and acquired immunity. Nat. Immunol. 4:1164-1165.

47. Benlagha, K., and A. Bendelac. 2000. CD1d-restricted mouse V $\alpha 14$ and human $\mathrm{V} \alpha 24 \mathrm{~T}$ cells: lymphocytes of innate immunity. Semin. Immunol. $12: 537-542$.

48. Godfrey, D.I., and M. Kronenberg. 2004. Going both ways: immune regulation via CD1d-dependent NKT cells. J. Clin. Invest. 114:1379-1388

49. Kronenberg, M. 2005. Toward an understanding of NKT cell biology: progress and paradoxes. Annu. Rev. Immunol. 23:877-900.

50. Rauch, J., J. Gumperz, C. Robinson, M. Skold, C. Roy, D.C. Young, M. Lafleur, D.B. Moody, M.B. Brenner, C.E. Costello, and S.M. Behar 2003. Structural features of the acyl chain determine self-phospholipid antigen recognition by a CD1d-restricted invariant NKT (iNKT) cell. J. Biol. Chem. 278:47508-47515.

51. Kronenberg, M., and Y. Kinjo. 2005. Infection, autoimmunity, and glycolipids: T cells detect microbes through self-recognition. Immunity. 22:657-659. 
52. Sriram, V., W. Du, J. Gervay-Hague, and R.R. Brutkiewicz. 2005 Cell wall glycosphingolipids of Sphingomonas paucimobilis are CD1dspecific ligands for NKT cells. Eur. J. Immunol. 35:1692-1701.

53. Ortaldo, J.R., H.A. Young, R.T. Winkler-Pickett, E.W. Bere Jr., W.J. Murphy, and R.H. Wiltrout. 2004. Dissociation of NKT stimulation, cytokine induction, and NK activation in vivo by the use of distinct TCR-binding ceramides. J. Immunol. 172:943-953.

54. Parekh, V.V., A.K. Singh, M.T. Wilson, D. Olivares-Villagomez, J.S Bezbradica, H. Inazawa, H. Ehara, T. Sakai, I. Serizawa, L. Wu, et al. 2004. Quantitative and qualitative differences in the in vivo response of NKT cells to distinct $\alpha$ - and $\beta$-anomeric glycolipids. J. Immunol. 173:3693-3706.

55. Brossay, L., O. Naidenko, N. Burdin, J. Matsuda, T. Sakai, and M Kronenberg. 1998. Structural requirements for galactosylceramide recognition by CD1-restricted NK T cells. J. Immunol. 161:5124-5128.

56. Sidobre, S., K.J. Hammond, L. Benazet-Sidobre, S.D. Maltsev, S.K. Richardson, R.M. Ndonye, A.R. Howell, T. Sakai, G.S. Besra, S.A. Porcelli, and M. Kronenberg. 2004. The T cell antigen receptor expressed by V $\alpha 14$ i NKT cells has a unique mode of glycosphingolipid antigen recognition. Proc. Natl. Acad. Sci. USA. 101:12254-12259.

57. Stewart-Jones, G.B., A.J. McMichael, J.I. Bell, D.I. Stuart, and E.Y. Jones. 2003. A structural basis for immunodominant human $\mathrm{T}$ cell receptor recognition. Nat. Immunol. 4:657-663.

58. Turner, S.J., K. Kedzierska, H. Komodromou, N.L. La Gruta, M.A. Dunstone, A.I. Webb, R. Webby, H. Walden, W. Xie, J. McCluskey, et al. 2005. Lack of prominent peptide-major histocompatibility complex features limits repertoire diversity in virus-specific $\mathrm{CD} 8^{+} \mathrm{T}$ cell populations. Nat. Immunol. 6:382-389.

59. Tynan, F.E., S.R. Burrows, A.M. Buckle, C.S. Clements, N.A. Borg, J.J. Miles, T. Beddoe, J.C. Whisstock, M.C. Wilce, S.L. Silins, et al. 2005. T cell receptor recognition of a 'super-bulged' major histocompatibility complex class I-bound peptide. Nat. Immunol. 6: 1114-1122.

60. Miles, J.J., D. Elhassen, N.A. Borg, S.L. Silins, F.E. Tynan, J.M. Burrows, A.W. Purcell, L. Kjer-Nielsen, J. Rossjohn, S.R. Burrows, and J. McCluskey. 2005. CTL recognition of a bulged viral peptide involves biased TCR selection. J. Immunol. 175:3826-3834.
61. Tynan, F.E., N.A. Borg, J.J. Miles, T. Beddoe, D. El-Hassen, S.L. Silins, W.J. van Zuylen, A.W. Purcell, L. Kjer-Nielsen, J. McCluskey, et al. 2005. High resolution structures of highly bulged viral epitopes bound to major histocompatibility complex class I. Implications for Tcell receptor engagement and T-cell immunodominance. J. Biol. Chem. 280:23900-23909.

62. Capone, M., D. Cantarella, J. Schumann, O.V. Naidenko, C. Garavaglia, F. Beermann, M. Kronenberg, P. Dellabona, H.R. MacDonald, and G Casorati. 2003. Human invariant V $\alpha 24-J \alpha Q$ TCR supports the development of CD1d-dependent NK $1.1^{+}$and NK $1.1^{-} \mathrm{T}$ cells in transgenic mice. J. Immunol. 170:2390-2398.

63. Godfrey, D.I., J. McCluskey, and J. Rossjohn. 2005. CD1d antigen presentation: treats for NKT cells. Nat. Immunol. 6:754-756.

64. Godfrey, D.I., D.G. Pellicci, and M.J. Smyth. 2004. Immunology. The elusive NKT cell antigen-is the search over? Science. 306:1687-1689.

65. Clements, C.S., L. Kjer-Nielsen, W.A. MacDonald, A.G. Brooks, A.W. Purcell, J. McCluskey, and J. Rossjohn. 2002. The production, purification and crystallization of a soluble heterodimeric form of a highly selected T-cell receptor in its unliganded and liganded state. Acta Crystallogr. D Biol. Crystallogr. 58:2131-2134.

66. Vagin, A., and A. Teplyakov. 2000. An approach to multi-copy search in molecular replacement. Acta Crystallogr. D Biol. Crystallogr. 56:1622-1624.

67. Brunger, A.T., P.D. Adams, G.M. Clore, W.L. DeLano, P. Gros, R.W Grosse-Kunstleve, J.S. Jiang, J. Kuszewski, M. Nilges, N.S. Pannu, et al. 1998. Crystallography \& NMR system: A new software suite for macromolecular structure determination. Acta Crystallogr. D Biol. Crystallogr. 54:905-921.

68. Murshudov, G.N., and M.Z. Papiz. 2003. Macromolecular TLS refinement in REFMAC at moderate resolutions. Methods Enzymol. 374:300-321.

69. Jones, T.A., J.Y. Zou, S.W. Cowan, and M. Kjeldgaard. 1991. Improved methods for building models in electron density maps and the location of errors in these models. Acta. Crystallogr. A. 47:110-119.

70. Matsuda, J.L., O.V. Naidenko, L. Gapin, T. Nakayama, M. Taniguchi, C.R. Wang, Y. Koezuka, and M. Kronenberg. 2000. Tracking the response of natural killer T cells to a glycolipid antigen using CD1d tetramers. J. Exp. Med. 192:741-753. 